\title{
Predictors for Obesity Hypoventilation Syndrome in Thai Population
}

\author{
Sarunya Saeseow, MD ${ }^{1,2 *}$, Paiboon Chattakul, MD ${ }^{1,2 *}$, Sittichai Khamsai, MD, \\ Panita Limpawattana, MD¹, Jarin Chindaprasirt, MD¹, Verajit Chotmongkol, MD¹, \\ Songkwan Silaruks, MD¹, Vichai Senthong, MD¹, Kittisak Sawanyawisuth, MD, $\mathrm{PhD}^{1,2}$ \\ 'Department of Medicine, Faculty of Medicine, Khon Kaen University, Khon Kaen, Thailand \\ ${ }^{2}$ Sleep Apnea Research Group, Research Center in Back, Neck and Other Joint Pain and Human Performance, \\ Research and Training Center for Enhancing Quality of Life of Working Age People, and Research and Diagnostic Center \\ for Emerging Infectious Diseases (RCEID), Khon Kaen University, Khon Kaen, Thailand
}

Sleep Med Res 2019;10(1):13-16

https://doi.org/10.17241/smr.2019.00318

We would like to correct the IRB number as written below.

Study protocol was approved by the Ethics Committee in Human Research, Khon Kaen University, Thailand (HE591130). 